\title{
Synthesis of comb bipolymers and their pour point depressing properties
}

\author{
Zhang Changqiao ${ }^{1 *}$, Gao Congcong ${ }^{1}$, Gao Fengfeng ${ }^{1}$, Wang Jian ${ }^{1}$, Zhang \\ Dawei $^{1}$, Wang Yan ${ }^{2}$ and $\mathrm{Xu}_{\text {Dawei }}{ }^{3}$ \\ ${ }^{1}$ School of Chemistry and Chemical Engineering, Shandong University, Jinan, Shandong 250061, China \\ ${ }^{2}$ Shandong Quality Certification Centre, Jinan, Shandong 250014, China \\ ${ }^{3}$ Shandong Product Quality Supervision \& Inspection Research Institute, Jinan, Shandong 250102, China \\ (C) China University of Petroleum (Beijing) and Springer-Verlag Berlin Heidelberg 2014
}

\begin{abstract}
A bipolymer maleic anhydride-methyl acrylate (MAMA) was synthesized from maleic anhydride and methyl acrylate based on molecular design. MAMA further reacted with oleylamine or octadecyl alcohol to generate two comb polymers called Oleamide-MAMA (NMAMA) and OctadecanolMAMA (OMAMA), respectively. The structure of both the polymers was confirmed by their infrared spectral analysis (IR), gel permeation chromatography analysis (GPC) and differential scanning calorimeter (DSC). Moreover, the pour point depressing (PPD) properties of these comb polymers were examined experimentally. Experimental results showed that besides the molecular weight and concentration of the polymers, the length of side chains and the number of functional groups also had great influence on the pour point depressing performance. The $\pi$ bonds and hydrogen bonds between depressants were the key factors for improving the pour point depressing properties. These results suggest that both OMAMA and NMAMA are potential pour point depressants for industry.
\end{abstract}

Key words: Maleic anhydride, comb polymers, pour point depressant, hydrogen bonds, molecular simulation

\section{Introduction}

With the rapid development of industry worldwide, the demand for crude oil and the production of crude oil is increasing year by year. But most of the oilfields are in the mid-late recovery stage, and the proportion of paraffin wax in crude oil is increasing rapidly, resulting in the crude oil having high viscosity and bad flow performance. The increased viscosity makes crude oil production and pipeline transportation more difficult. Therefore, development of technology for high viscosity crude oil transportation has become an important issue (Yang, 2006; Tokuma et al, 2003).

Currently, crude oil pour point depression is used to solve these problems (Wang et al, 2007; Prahl, 2000). For low-viscosity crude oil, most pour point depressants are synthesized based on ethylene vinyl acetate (EVA) polymer. For high-viscosity crude oil, although the study of pour point depressants based on acrylic ester and maleic anhydride copolymers have been reported (Du et al, 2012), but studies on the effect of functional groups, polymer structure and thermal stability on the paraffin crystallization process are still relatively limited (Deshmukh and Bharambe, 2009;

*Corresponding author. email: zhangchqiao@sdu.edu.cn

Received November 30, 2012
Mieulet, 1966).

In this paper, one bipolymer called MAMA was first synthesized from maleic anhydride and methyl acrylate. Then MAMA reacted with oleylamine or octadecyl alcohol to produce two comb polymers NMAMA and OMAMA, respectively. The structures and properties of the three polymers were studied by infrared spectroscopy, gel permeation chromatography (GPC), differential scanning calorimetry (DSC) and scanning electron microscopy (SEM) (Lehn, 1995; Soni and Kiranbala, 2010; Tang et al, 2009; Zhu, 2012). The paraffin crystallization behavior and pour point depressing properties of the crude oil were also studied from the aspects of polymer functional groups, polymer structures and thermal stability.

\section{Experimental}

Free radical polymerizations are mainly bulk polymerization, solution polymerization, emulsion polymerization and suspension polymerization (Pan, 2007). Considering the difficulty in operation of their technological processes, the solution polymerization and emulsion polymerization are usually adopted (Beristain et al, 2012; Allan et al, 2012); They are also suitable for the copolymerization of acrylic ester and maleic anhydride. But in emulsion polymerization method, it is not easy to 
control the molecular weight of the polymers, and polymers with large molecular weight usually have bad oil solubility. Therefore, we adopted the solution polymerization method (Galicia et al, 2011; Frauendorfer and Hergeth, 2011) in this work.

\subsection{Raw materials}

The materials used in experiment are shown in Table 1.

Table 1 Raw materials

\begin{tabular}{|c|c|c|}
\hline Materials & Purity & Manufacturer \\
\hline Maleic anhydride & AP & $\begin{array}{l}\text { Tianjin Kemiou Chemical Reagent Co., } \\
\text { Ltd., China }\end{array}$ \\
\hline Acrylic acid methyl ester & AP & $\begin{array}{c}\text { Shanghai Chemical Reagent company, } \\
\text { China }\end{array}$ \\
\hline $\mathrm{ABIN}$ & AP & $\begin{array}{l}\text { Shanghai Hervey Chemical Industrial } \\
\text { limited company, China }\end{array}$ \\
\hline High pure nitrogen & $99.99 \%$ & $\begin{array}{l}\text { Ji'nan Deyang Special Gas Company, } \\
\text { China }\end{array}$ \\
\hline Oleylamine & AP & J\&K Scientific Ltd., China \\
\hline Octadecyl alcohol & AP & $\begin{array}{c}\text { Tianjin Damao Chemical Reagent } \\
\text { factory, China }\end{array}$ \\
\hline Benzene & AP & $\begin{array}{c}\text { Laiyang Kangde Chemicals Co., Ltd., } \\
\text { China }\end{array}$ \\
\hline Tetrahydrofuran & AP & $\begin{array}{l}\text { Sinopharm Chemical Reagent Co., Ltd., } \\
\text { China }\end{array}$ \\
\hline Hexane & AP & $\begin{array}{c}\text { Tianjin Damao Chemical Reagent } \\
\text { factory, China }\end{array}$ \\
\hline Ethanol & AP & $\begin{array}{l}\text { Tianjin Fuyu Fine Chemical Co., Ltd., } \\
\text { China }\end{array}$ \\
\hline
\end{tabular}

\subsection{Experimental device}

The experimental device is shown in Fig. 1

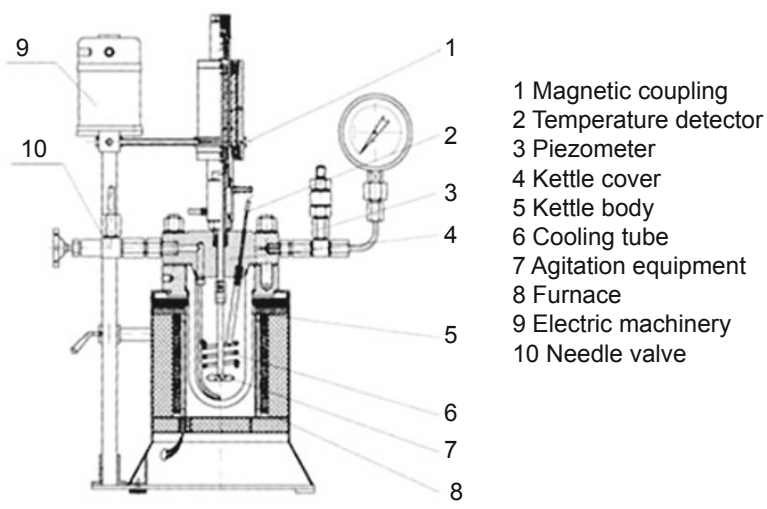

Fig. 1 Experimental device for emulsion polymerization-GSH reactor

\subsection{Preparation of MAMA}

The mixture of acrylic acid methyl ester and maleic anhydride (in a molar ratio of 1:1) was dissolved in benzene in a polymerization reactor which was equipped with a nitrogen inlet. Then it was heated to $60-80{ }^{\circ} \mathrm{C}$ for reaction for $18 \mathrm{~h}$ with an initiator ABIN (1 wt $\%$ ) while being stirred. Finally, the reaction product was added to excess petroleum ether, and the resultant white precipitate was the product polymer MAMA. The reaction of the three copolymers can be given as follows.

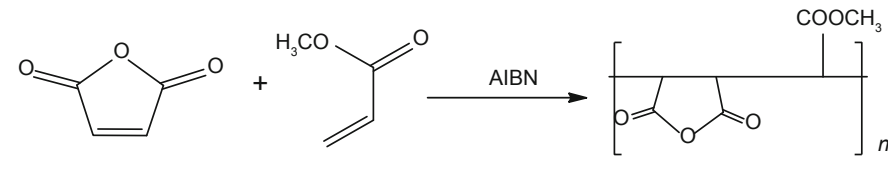

\subsection{Preparation of NMAMA}

The mixture of MAMA polymers and oleylamine (in a molar ration of 1:2) were dissolved in tetrahydrofuran (THF), and reacted at $20 \pm 0.5^{\circ} \mathrm{C}$ for $20-32 \mathrm{~h}$ under vigorous stirring. Then excess hexane was added in 10:1 volume ratio and a white precipitate (crude product of polymer NMAMA) was obtained. The product was further purified 3 times in an excess THF, and dried under vacuum at $50{ }^{\circ} \mathrm{C}$ for $24 \mathrm{~h}$. The reaction of the three copolymers can be given as follows:

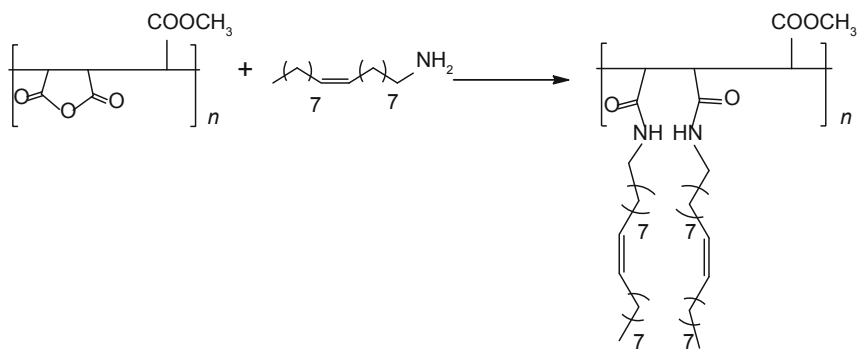

\subsection{Preparation of OMAMA}

The polymer MAMA was added to molten octadecyl alcohol, and reacted at $100-110{ }^{\circ} \mathrm{C}$ for $8-12 \mathrm{~h}$ under vigorous stirring. Then the reaction product was added to ethanol, and the unreacted octadecyl alcohol was removed by ultrasonic cleaning at $60{ }^{\circ} \mathrm{C}$. Finally, the obtained product was dried under vacuum at $50{ }^{\circ} \mathrm{C}$ for $24 \mathrm{~h}$. The reaction of the three copolymers can be given as follows:

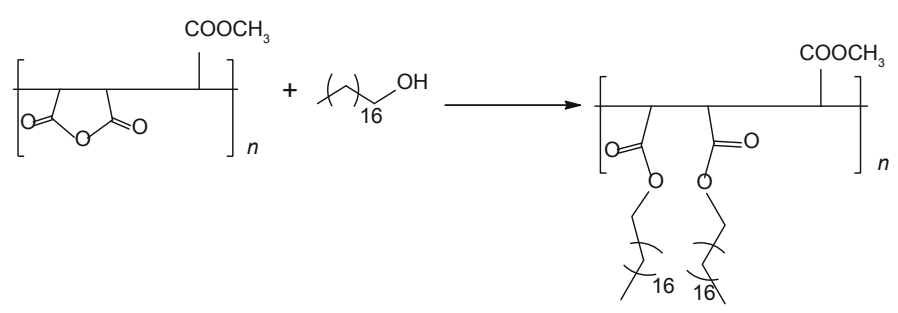

\subsection{Characterization and analysis of pour point depressants}

\subsubsection{Infrared spectrum}

The sample for infrared spectrum analysis was prepared by the $\mathrm{KBr}$ disk method. The infrared spectrum analysis was carried out with a Tensor 27 Fourier transform infrared spectrometer made by Bruker, Germany. The resolution ratio was $4 \mathrm{~cm}^{-1}$, and the number of scans was 64 .

\subsubsection{Gel chromatography}

Gel chromatography analysis was performed with a Waters 2410 Gel permeation chromatograph (GPC) (Waters Company, USA), which was equipped with a Waters 515 system, a 2410 refractive index detector and two styragel gel columns, and calibrated with narrow molecular weight polystyrene standards, to estimate the molecular weights 
and polydispersity of the synthesized polymers. THF was used as a mobile phase at a flow rate of $1.0 \mathrm{~mL} / \mathrm{min}$. The concentrations of polymer samples were in the range of 2.0$3.0 \mathrm{mg} / \mathrm{mL}$, and the injection volume was $50 \mu \mathrm{L}$ for each analysis. The temperature of columns and detectors was maintained at $35^{\circ} \mathrm{C}$.

\subsubsection{Differential scanning calorimetry}

The differential scanning calorimetry analysis was conducted with a DSC822e (Mettler Company, Switzerland) at a flow rate of $\mathrm{N}_{2}$ of $50 \mathrm{~mL} / \mathrm{min}$, and the increasing temperature rate of $10^{\circ} \mathrm{C} / \mathrm{min}$.

\subsubsection{Scanning electron microscopy}

The scanning electron microscopy was conducted with a SEM JSM-7600F (JEOL, Japan) at an acceleration voltage of $5-30 \mathrm{kV}$, and an electron beam current of $10^{-13}-2 \times 10^{-9} \mathrm{~A}$.

\subsubsection{Evaluation of pour point depressing}

The samples for evaluation of their pour point depressing properties were prepared by a typical standard method (Chen et al, 2010). Polymer was dissolved in xylene to make different concentrations of mother liquor. The mother liquor was added into crude oil $(1.5 \mathrm{~mL}$ mother liquor per $10 \mathrm{~g}$ crude oil), and then the mixture was heated to $45^{\circ} \mathrm{C}$ and kept at 45 ${ }^{\circ} \mathrm{C}$ for 30 minutes under vigorous stirring. Using a petroleum product solidifying point tester SYD-510G(Shanghai Changji Chemical Instruments Company, with an accuracy of 0.1 ${ }^{\circ} \mathrm{C}$ ), the pour point was determined according to method SY/ T0537-2008.

\section{Results and discussion}

\subsection{Structural characterization of pour point depressants}

\subsubsection{Infrared spectrum}

Fig. 2 shows the IR spectrum diagram of MAMA, NMAMA and OMAMA. It can be seen that, for MAMA, the $\mathrm{C}-\mathrm{H}$ stretching vibrations of methyl and methylene groups appeared at around $2,962 \mathrm{~cm}^{-1}$, and $\mathrm{C}=\mathrm{O}$ and $\mathrm{C}-\mathrm{O}$ stretching vibrations of ester groups were at $1,744 \mathrm{~cm}^{-1}$ and 1,161 $\mathrm{cm}^{-1}$, respectively. The absorption peaks of maleic anhydride appeared at $1,858 \mathrm{~cm}^{-1}$ and $1,789 \mathrm{~cm}^{-1}$. While the absorption near $2,300 \mathrm{~cm}^{-1}$ belonging to the initiator disappeared, implying that the initiator was exhausted. It suggests that the two reactants were totally polymerized to the product, MAMA (Zhou, 2000; Zhang, 2006).

For NMAMA (see Fig. 2), the peaks at 2,926 $\mathrm{cm}^{-1}$ and $2,866 \mathrm{~cm}^{-1}$ were assigned to the $\mathrm{C}-\mathrm{H}$ stretching vibration of methyl and methylene groups, and the absorption peaks at $1,736 \mathrm{~cm}^{-1}$ and $1,168 \mathrm{~cm}^{-1}$ were attributed to $\mathrm{C}=\mathrm{O}$ and $\mathrm{C}-\mathrm{O}$ stretching vibration. The peaks belonging to MAMA $(1,858$ $\mathrm{cm}^{-1}$ and $1,789 \mathrm{~cm}^{-1}$ shown in Fig. 4) disappeared. The characteristic band at $1,568 \mathrm{~cm}^{-1}$ was the absorption of $\mathrm{C}=\mathrm{C}$ stretching vibration of the product introduced by reactant oleylamine. The absorption peaks at $1,062 \mathrm{~cm}^{-1}$ and 1,664 $\mathrm{cm}^{-1}$ were attributed to the existence of amide. This spectrum showed that oleylamine and MAMA were completely reacted, and polymerized to NMAMA.

For OMAMA (Fig. 2), the bands at $2,921 \mathrm{~cm}^{-1}$ and 2,848 $\mathrm{cm}^{-1}$ showed the $\mathrm{C}-\mathrm{H}$ stretching vibration of methyl and methylene groups. The $\mathrm{C}=\mathrm{O}$ and $\mathrm{C}-\mathrm{O}$ absorption peaks of the ester appeared at $1,710 \mathrm{~cm}^{-1}$ and $1,063 \mathrm{~cm}^{-1}$. The absorptions at $1,858 \mathrm{~cm}^{-1}$ and $1,789 \mathrm{~cm}^{-1}$ belonging to the anhydride of NMA disappeared, indicating that MAMA was converted to product, and the octadecanol was introduced into OMAMA.

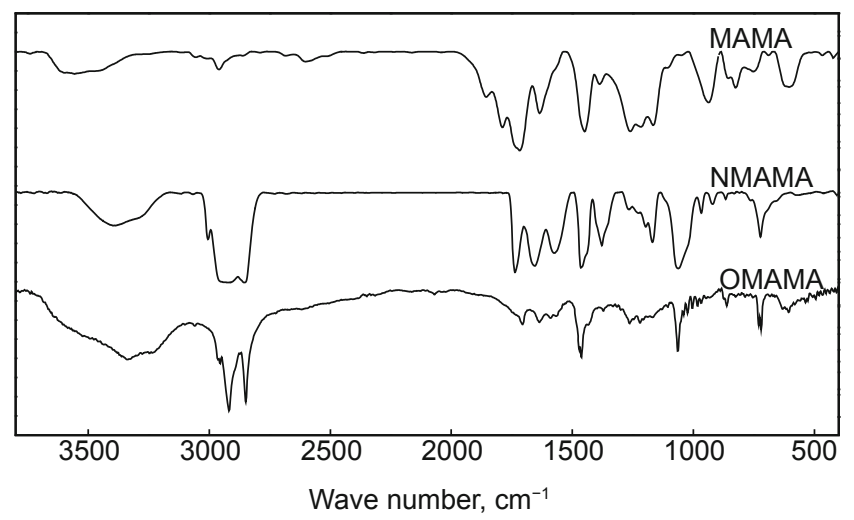

Fig. 2 IR spectrum of MAMA, NMAMA and OMAMA

\subsubsection{Gel chromatography}

The molecular weights (Mw) of three polymers were all of the order of a hundred thousand, and their dispersancy indexes were in the range of 2.5-2.6. But the molecular weight of OMAMA is smaller than that of NMAMA. Moreover, octadecyl alcohol and oleylamine have almost the same relative molecular weight, indicating that the anhydride ring of NMAMA can be opened and grafted (Hagel, 2011; Kostanyan and Voshkin, 2011).

Table 2 GPC data of the three polymers

\begin{tabular}{cccc}
\hline Polymers & $\begin{array}{c}\text { Number-average } \\
\text { molar mass }(\mathrm{Mn})\end{array}$ & $\begin{array}{c}\text { Molecular } \\
\text { weight }(\mathrm{Mw})\end{array}$ & $\begin{array}{c}\text { Dispersancy } \\
\text { index }\end{array}$ \\
\hline MAMA & 54769 & 151126 & 2.62 \\
OMAMA & 78652 & 203749 & 2.59 \\
NMAMA & 85423 & 256741 & 2.50 \\
\hline
\end{tabular}

\subsubsection{Differential scanning calorimetry}

From the aspect of molecular structure, the glass transition is one relaxation phenomena of the amorphous part of polymers from frozen to plastic condition. At a temperature lower than glass transition temperature $\left(T_{\mathrm{g}}\right)$, polymers are frozen and the molecular chains and partial chains are hard to move. Under the same experimental conditions, the main factor influencing $T_{\mathrm{g}}$ is the structure of polymers. The flexibility of polymers depends on the structural property of their main chains, therefore, the polymers with flexible chains corresponds to a low $T_{\mathrm{g}}$ (Sabadini et al, 2010).

The glass transition temperature $\left(T_{\mathrm{g}}\right)$ of MAMA is $130{ }^{\circ} \mathrm{C}$. However, the $T_{\mathrm{g}}$ of NMAMA and OMAMA are $115^{\circ} \mathrm{C}$ and $50{ }^{\circ} \mathrm{C}$, respectively (see Fig. 3), indicating that the flexibility of OMAMA molecular chains is better than that of NMAMA, attributed to the existence of hydrogen bonds between the carboxyl groups of OMAMA (Hutchinson, 2009). 


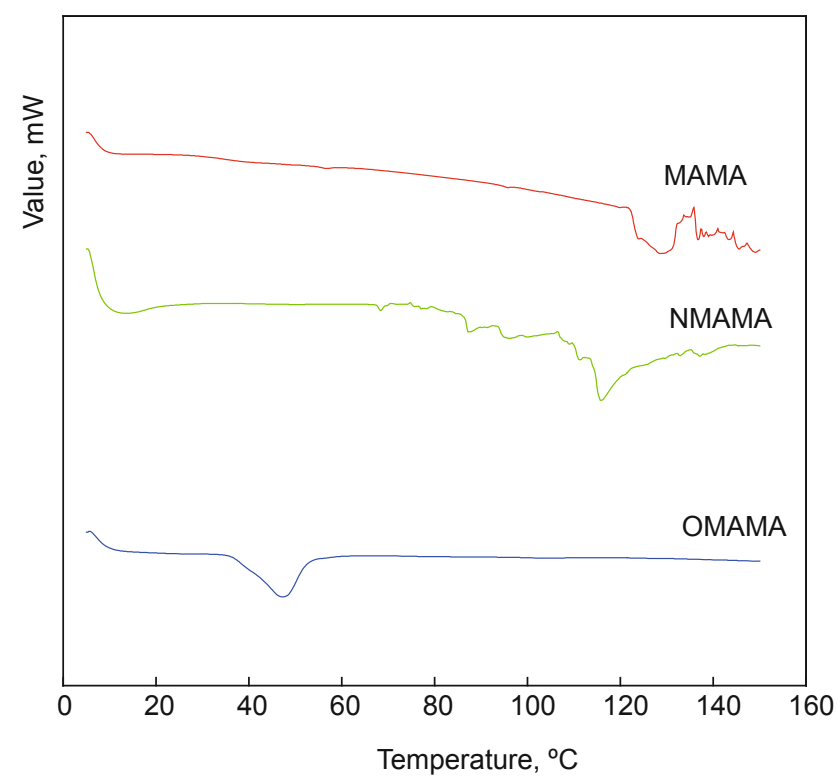

Fig. 3 DSC diagram of MAMA, NMAMA and OMAMA

\subsection{Pour point depressing properties and mechanisms of polymers}

\subsubsection{Molecular dynamical simulation of pour point depressants}

In crude oil, the precipitation of paraffin wax is formed through a three-dimensional network structure at low temperature (Yi and Zhang, 2011; Dilawaravk and Srivatavasp, 1994). There exist $\pi$ bonds among the polymers synthesized in this paper, which are accompanied with intermolecular hydrogen bonds. Because hydrogen bonding interactions are stronger than the van der Waals force, paraffin molecules can be combined more easily with hydrogen bonds. This has an effect on paraffin morphology and the forming process of its network structure, preventing or weakening the formation of three-dimensional network structure (Olayo et al, 2004). As a result, the polymers have excellent pour point depressing properties.

A simulation model was created in a virtual cube box with a $6.0 \mathrm{~nm}$ side, comprising $10 \mathrm{comb}$ polymers NMAMA and xylene as solvent molecules. The virtual temperature was set to $303 \mathrm{~K}$, and the Construction tool in Amorphous Cell Tools module was used to build the model. The initial and simulated structures of polymers were compared under the COMPASS force field (Jin et al, 2003; Ilnytskyi et al, 2008).

The micro behavior of comb polymers can be studied through the aggregation structure. As is shown in Fig. 4 , system molecules had a certain aggregation after a long dynamic simulation. The main driving force for the aggregation of these compounds was $\pi$ bonds and hydrogen bonds. Therefore, the properties of polymers' energy were studied during the process of dynamic molecular simulation.

The model was optimized using the Minimize tool, and then the Dynamics tool in the Discover Tools module was used for molecular dynamic calculation. The kinetic parameters were set as follows: NVT system of $303 \mathrm{~K}$, number of steps of 10,000, time step of $1.0 \mathrm{fs}$, dynamics time of $10.0 \mathrm{ps}$, frame output every: 50 steps.

The $\pi$ bonds and hydrogen bonds in polymers affected paraffin morphology and the forming process of network structure, subsequently preventing or weakening the formation of paraffin three-dimensional network structure, so that polymers had fine pour point depressing properties. The molecular dynamical simulation result in Fig. 5 showed that, the potential energy gradually increased to a stable value, however, the non-bond energy was relatively small and did not change significantly.

To sum up, molecules had a certain aggregation after the long dynamic simulation; the potential energy gradually increased to a stable value, and structure became stable. So theoretically the polymers have pour point depressing properties.

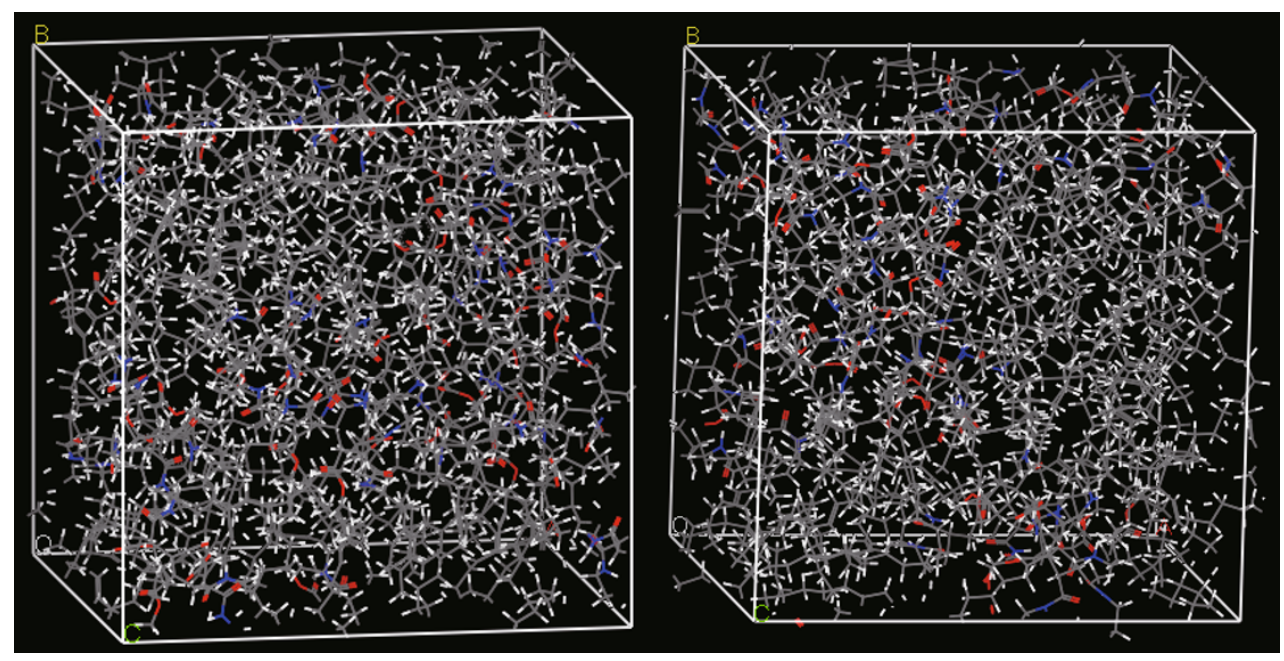

Fig. 4 Initial and simulated structures of comb polymers

\subsubsection{Pour point depressing}

The crude oil used in experiment was from the Daqing and Jilin oil fields, China. The pressure of the sampled crude oil is $0.26 \mathrm{MPa}$, the pour point of crude oil is $38^{\circ} \mathrm{C}$, and wax content in crude oil is $29.9 \%$.

Fig. 6 shows the relationship between the concentration 


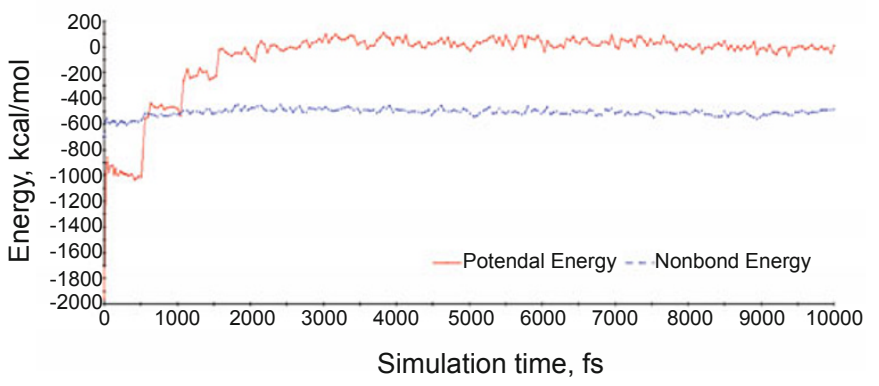

Fig. 5 The change of potential and non-bond energy during molecular dynamical calculation

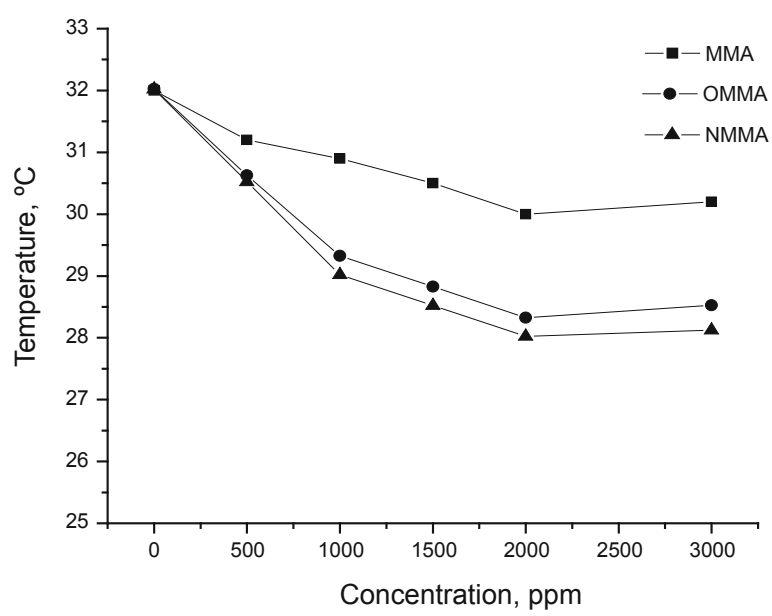

Fig. 6 Oil pour point change with the concentration of polymers

of polymers and the pour point of crude oil. It can be seen that the pour point of crude oil decreased with increasing concentration of the polymers. When the concentration of the polymers was equal to or larger than 2,000 ppm, the pour point temperature of crude oil changed very little. Therefore, the optimal concentration of polymers is $2,000 \mathrm{ppm}$. The pour point of crude oil was decreased by only $2.0^{\circ} \mathrm{C}$ with MAMA, whereas it was decreased by $4.3^{\circ} \mathrm{C}$ with NMAMA and OMAMA, showing that the modified polymers NMAMA and OMAMA have significantly better pour point depressant properties.

\subsubsection{Pour point depressing mechanisms of polymers}

The solubility of polymers can be reduced because of their long side chains, while polymers with short side chains have high solubility that can efficiently prevent the crystallization of paraffin. There are both long side chains and short side chains in the NMAMA and OMAMA structures. If the polymers contain only long carbon chains, under normal circumstances, it will be of a spiral structure and cannot provide attachment points for paraffin crystallization. The combination of short and long chains in a polymer's structure gives it with good solubility in crude oil, as a result, polymers prepared in this work had good pour point depressing effect as crude oil additives even at low temperature.

The $\pi$ bonds in polymers played two roles. First, it can provide sufficient points for the crystallization. Second, the carboxyl groups and the other side chains can form strong hydrogen bonds, which can reduce the glass transition temperature of the polymers. The hydrogen bonds can provide different attachment points for paraffin crystallization, and guide them to grow in right direction. Thus, paraffin will not crystallize by itself, and not hinder the flowability of crude oil.

The SEM photographs of the three samples (MAMA, NMAMA and OMAMA) are shown in Figs. 7, 8 and 9. The snow-like picture of MAMA indicated the crystallization of paraffin. The pictures of OMAMA and NMAMA were of small-and-uniformly-distributed particles, showing the dispersancy of paraffin crystals had been improved greatly. It suggested that the paraffin grew up in a certain direction when MAMA was added to crude oil. However, when OMAMA or NMAMA was added to crude oil, the paraffin crystals became to be small-and-uniformly distributed particles due to different attachment points, thus preventing paraffin from further crystallization and reducing the pour point of crude oil.

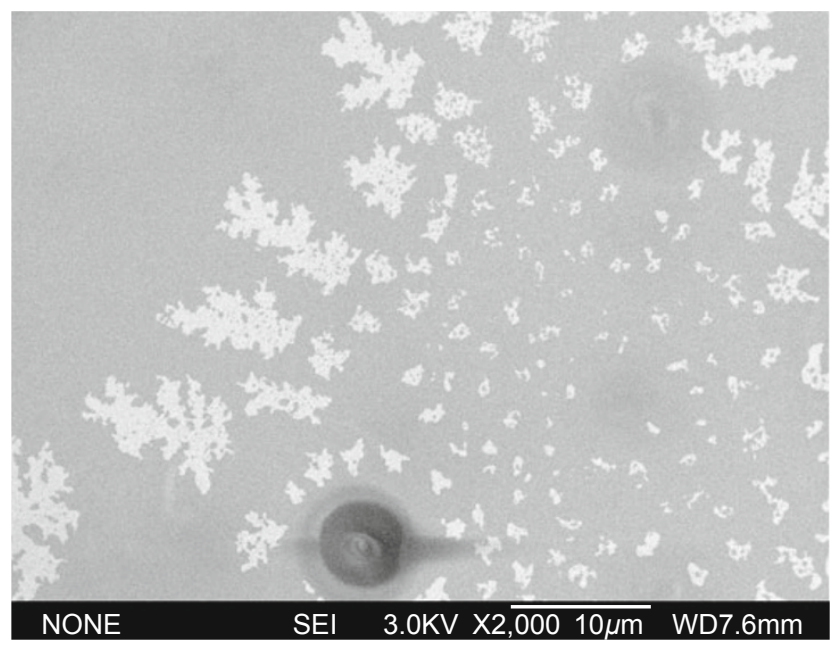

Fig. 7 SEM photograph of MAMA

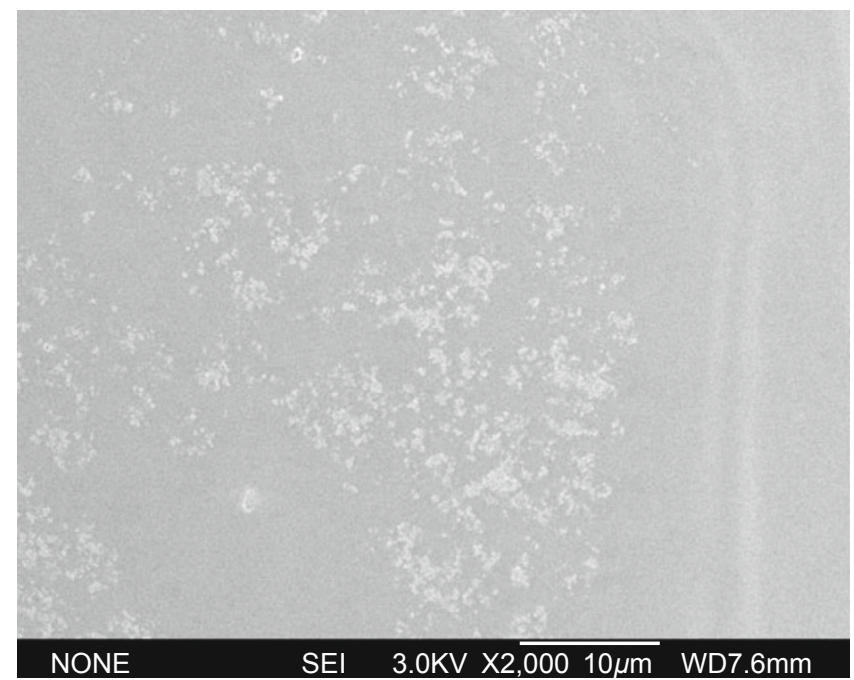

Fig. 8 SEM photograph of NMAMA 


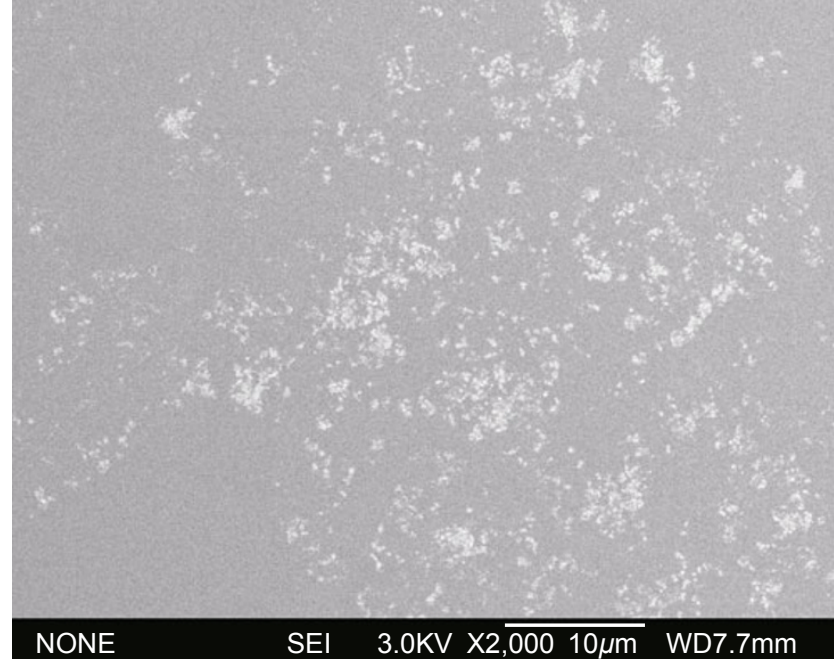

Fig. 9 SEM photograph of OMAMA

\section{Conclusions}

In this study, two novel comb polymers OMAMA and NMAMA were synthesized by changing the MAMA branches and polar functional groups. Their structures were characterized by IR and GPC. Then the pour point depressing properties and mechanisms of polymers were studied by DSC and SEM. Results show that, besides the molecular weight and concentration of polymers, the length of side chains and the number of functional groups also have obvious influence on the depressing ability. The $\pi$ bonds and hydrogen bonds in the molecular structures of depressants are the key factors to improve the pour point depressing properties. These results suggest that both OMAMA and NMAMA are potential pour point depressants for industry.

\section{References}

Allan L E N, Perry M R and Shaver M P. Organometallic mediated radical polymerization. Progress in Polymer Science. 2012. 37 (1): 125-128

Beristain M F, Jimenez-Solomon M F, Ortega A, et al. Magnetic properties of polymerized diphenyloctatetrayne. Materials Chemistry and Physics. 2012. 136 (2): 1126-1128

Chen W H, Zhao Z C and Yin C Y. The interaction of waxes with pour point depressants. Fuel. 2010(89): 1127-1132

Deshmukh S and Bharambe D. Evaluation of effect of polymeric pour point depressant additives on Indian waxy crude oil. Petroleum Science and Technology. 2009. 27(18): 2096-2098

Dilawaravk and Srivatavasp. Crystallization characteristics of waxes from undoped crude oil. Science and Technology. 1994. 47(4): 150152

Du T, Wang S, Liu H, et al. The synthesis and characterization of methacrylic acid ester-maleic anhydride copolymer as a lube oil pour point depressant. Petroleum Science and Technology. 2012. 30(2): 210-212

Frauendorfer E and Hergeth W-D. Industrial Polymerization Monitoring. Macromolecular Symposia. 2011. 302(1): 1-5

Galicia J A, Cousin F, Dubois E, et al. Local structure of polymeric ferrogels. Journal of Magnetism and Magnetic Materials. 2011. 323(10): 1210-1215

Hagel L. Gel filtration: Size exclusion chromatography. The Free Encyclopedia. 2011. 54: 50-62

Hutchinson J M. Determination of the glass transition temperature. Journal of Thermal Analysis and Calorimetry. 2009. 98(3): 579-589

Ilnytskyi J, Neher D, Wilson M, et al. Molecular dynamics simulations of various branched polymeric liquid crystals. Molecular Crystals and Liquid Crystals. 2008. 496: 185-190

Janis Hunt. Oil and energy trends: a monthly publication of international energy statistics and analysis. Crude Oil Production. 2012. 37(2): 1825

Jin Y, Liu W and Gong L. A study of reaction mechanism of the nucleophilic reagent in the cationic polymerization of isobutene with molecular simulation. CHINA ELASTOMERICS. 2003. 13(6): 40-45

Kostanyan A and Voshkin A. Analysis of cyclic liquid chromatography. Theoretical Foundations of Chemical Engineering. 2011. 45(1): 6772

Lehn J M. Supramolecular chemistry: concepts and perspectives. VCH, Welnhelm. 1995

Mieulet P. A new pour point depressant. World Oil. 1966. 5(10): 95-101

Olayo M G, Cruz G J, Ordoñez E, et al. Molecular simulation of plasma polymerized polyaniline-iodine compounds. Polymer. 2004. 45(10): 3565-3575

Pan Z R. Polymer Chemistry. Beijing: Chemical Industry Press. 2007. 26-44 (in Chinese)

Prahl U. Influence of asphaltenes on the crystallization of paraffins. Erdoel Erdgas Kohle. 2000. 116(2): 95

Sabadini E, Francisco K R and Bouteiller L. Bis-urea-based supramolecular polymer: The first self-assembled drag reducer for hydrocarbon solvents. Langmuir. 2010. 26(3): 1482-1486

Soni H P and Kiranbala. Designing maleic anhydride- $\alpha$-olifin copolymeric combs as wax crystal growth nucleators. Fuel Processing Technology. 2010(91): 997-1004

Tang X H, Yan S Q and Wang S X. Synthesis of acrylic ester-styrenemaleic anhydride pour point depressant. Journal of Lanzhou University. 2009. 45(1): 69-72 (in Chinese)

Tokuma F, Hiroshi U and Shiro K. Synthesis of ultrahigh molecular weight polyphenols by oxidative coupling. Macromolecules. 2003. 36(22): 8213-8215

Wang D, Zhao X F and Ma Chunxi. Research on high wax crude oil compounds. Advances in Fine Petrochemicals. 2007. (12): 31-34 (in Chinese)

Yang X H. Design and Management of Oil Pipelines. Dongying: China University of Petroleum Press. 2006. 76-155 (in Chinese)

Yi S and Zhang J J. Relationship between waxy crude oil composition and change in the morphology and structure of wax crystals induced by pour-point-depressant beneficiation. Energy \& Fuels. 2011. 25(4): $1685-1686$

Zhang F Y. Synthesize and characterize of crude oil viscosity reducers. Dissertation for master's degree. Southwest Petroleum University. 2006. 20-42

Zhou F S. The improvement mechanisms of flowability and the preparation and application of copolymeric viscosity reducers for crude oils. Dissertation for Doctor's degree. Xi'an Jiaotong University. 2000. 31-52

Zhu Q L. Study on the reaction of dihydromyrcenol and maleic anhydride. Shandong Chemical Engineering. 2012. 41(1): 8-16 (in Chinese)

(Edited by Zhu Xiuqin) 